\title{
X-LAUDO: APLICATIVO EM TELEMEDICINA PARA COMPARTILHAMENTO DE IMAGENS MÉDICAS E LAUDOS REFERENTES
}

\author{
A. J.A. Silva*, G.C.M. Almeida*, I. Bernardes*. J.T. Faria*, L.A.P.B. Vieira e A.C.Patrocínio* \\ *Faculdade de Engenharia Elétrica/UFU, Uberlândia, Brasil \\ e-mail: giuliac.mendonca@gmail.com
}

\begin{abstract}
Resumo: Este artigo apresenta um aplicativo desenvolvido para o compartilhamento de imagens médicas que visa atender unidades básicas de saúde, já que em muitos hospitais, principalmente os de menor porte, existe a problemática da falta de médico especialista na área de radiologia, o qual efetuaria a análise e o laudo das imagens obtidas. Desta forma, o aplicativo seria uma ponte de comunicação entre o técnico em radiologia e o médico radiologista dessas unidades básicas de saúde com hospitais de maior porte. O software desenvolvido foi implementado no compilador Microsoft Visual Studio 2013, em C-Sharp, possuindo telas de acesso, cadastro e compartilhamento de imagens padrão DICOM, além de comentários (laudos) a respeito das mesmas.
\end{abstract}

Palavras-chave: Telemedicina, telerradiologia, imagem médica.

Abstract: This paper presents an application developed for medical image sharing that aims to meet basic health centers, as in many hospitals, especially smaller ones, there is the problem of shortage of medical specialist in radiology, who would implement the analysis and the report of the images obtained.

In this way, the application would be a bridge of communication between the radiographer and radiologist from these basic health centers with larger hospitals.

The software developed was implemented in Microsoft Visual Studio 2013 compiler in C-sharp language, having access screens, registration and sharing DICOM standard images and comments (report) about them.

Keywords: Telemedicine. Teleradiology, medical image.

\section{Introdução}

A radiologia é um ramo da medicina que visa identificar alterações no corpo humano, através da obtenção de imagens geradas por raios-X ou em exames de ressonância magnética. $\mathrm{O}$ exame de raios-X é mais usual como o método para avaliar várias patologias. Ele é um exame que não possui contra-indicações para sua realização, além de ser feito sem o uso de contraste. Outra vantagem deste exame é o baixo custo e rápido tempo de realização, assim como também o diagnóstico, já que logo após a geração da imagem, o médico pode determinar seu laudo.

Além da possibilidade de detecção de alterações fisiológicas, o exame de raios-X é utilizado para análise de fraturas ósseas. A traumatologia é uma especialidade médica que investiga, diagnostica e trata enfermidades que estão relacionadas com fraturas ósseas [1].

O exame radiológico é realizado por um técnico em radiologia, responsável por operar o equipamento de raios-X. Esse técnico é um profissional capacitado, formado em curso especializado para que ele seja capacitado a realizar tal procedimento. $\mathrm{O}$ diagnóstico de uma imagem radiológica é feito por um médico especializado em radiologia, denominado radiologista. $\mathrm{O}$ radiologista é responsável pela análise e interpretação de imagens de raios-X e dessa forma, responsável pela emissão de laudos e relatórios acerca dos exames radiológicos.

A telemedicina, segundo a Organização Mundial de Saúde (OMS), é a "prestação de cuidados de saúde em situações em que a distância é um fator crítico, por qualquer profissional de saúde usando tecnologias de informação e de comunicações para o intercâmbio de informação relevante para o diagnóstico, para o tratamento e a prevenção da doença e danos físicos, pesquisa e avaliação, e para a formação continuada dos prestadores, subordinada a objetivos de melhoria da saúde dos indivíduos e das comunidades" [2].

A telerradiologia é conceituada como a transmissão digital de imagens radiográficas por meio de tecnologias da informação e de comunicação, com o objetivo de permitir o diagnóstico à distância ou emitir uma segunda opinião especializada [3]. Ao ser empregado, a telerradiologia possibilita um aumento no número de exames radiológicos realizados em pequenas unidades de saúde, bem como um aumento na rapidez de diagnóstico e tratamento das patologias apresentadas, e, consequentemente, menores demanda em grandes centros de tratamento 
Sabendo da necessidade de transferências de indivíduos que apresentam características de fraturas ósseas para grandes centros de tratamento, o aplicativo X-laudo busca desenvolver uma solução para este problema através da telemedicina. $\mathrm{O}$ aplicativo foi gerado enfatizando um dos ramos da telemedicina que se volta para o compartilhamento de imagens radiológicas entre dois locais distintos: a telerradiologia.

Esse aplicativo foi baseado no emprego hipotético de telerradiologia entre uma unidade básica de saúde e o Hospital de Clínicas da Universidade Federal de Uberlândia (HC-UFU). Ambas as unidades de saúde são subordinadas ao Sistema Único de Saúde, e, dessa forma, tem acesso ao sistema de dados do mesmo. Foi considerado que, sempre quando solicitado, haverá um especialista em radiologia no HC-UFU, além da existência da estrutura física necessária para a implantação do sistema.

O software usado foi implementado no compilador Microsoft Visual Studio 2013, em C-Sharp, possuindo telas de acesso, cadastro e compartilhamento de imagens padrão DICOM, além de comentários (laudos) a respeito das mesmas.

\section{Materiais e métodos}

Este aplicativo foi desenvolvido por um sistema que contém um software de telecomunicação, possibilitando o compartilhamento de imagens radiológicas em padrão DICOM (Digital Imaging and Communications in Medicine), o qual é um protocolo de comunicação padrão para imagens adotado pelo Colégio Americano de Radiologia.

O X-laudo funciona como comunicação entre o técnico em radiologia e o médico radiologista, atuante em outra unidade de saúde, que no caso é o HC-UFU. Após a realização do exame de raios-X, o técnico em radiologia disponibiliza se necessário (já que o exame precisa ser solicitado pelo médico plantonista a outro profissional, para melhor diagnóstico) as imagens radiográficas no aplicativo $\mathrm{X}$-laudo disponíveis na unidade básica de saúde. O médico radiologista - ou pode-se falar no plural, como médicos radiologistas, já que o aplicativo não é exclusivo de apenas um especialista nessa área; responsável pelo conteúdo recebido no aplicativo verifica a existência de laudos solicitados, e realiza as observações necessárias sobre as possíveis lesões e suas características, como localidade, estruturas afetadas, entre outros, além de também indicar a forma de tratamento mais adequado.

Após essa análise, o médico radiologista envia o laudo para o técnico, onde o mesmo encaminharia para o médico que solicitou o exame na unidade básica de saúde. Esse sistema, para obter sucesso, seria executado em ambas as unidades.

No software do aplicativo, existem ferramentas básicas de manipulação de imagens, como formatação de tamanho da imagem original assim como alteração no contraste e brilho da mesma.

O software foi programado no compilador Microsoft Visual Studio 2013 em linguagem C-Sharp. Nele existem quatro telas básicas de funcionamento, sendo a primeira a Tela de Cadastro de Profissional. Nesse espaço há todos os dados necessários dos profissionais que utilizaram o software, bem como informações de login e senha para acesso. As informações são armazenadas em um banco de dados gerados a partir de armazenamento na linha Access do pacote Microsoft Office 2013 contendo informações pertinentes ao cadastrado (Código de cadastro, Nome, CPF, CRM, RG, Endereço, Telefone, Email, Login, Senha, Profissional, Instituição).

A segunda é a Tela Acesso. Nesta tela, o usuário poderá preencher o campo com seu login e senha e, a partir dela, acessar sua tela de trabalho. Ao realizar o cadastro, o software separa cada grupo profissional (técnico em radiologia ou médico radiologista). Assim, o profissional só terá acesso à sua tela de interesse, otimizando o funcionamento do programa.

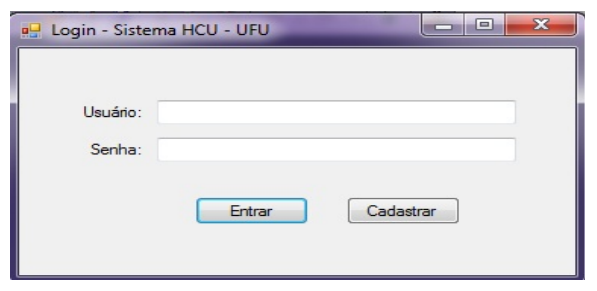

Figura 1 - Imagem da Tela Acesso do aplicativo Xlaudo.

A terceira é a Tela Técnico. O técnico radiologista poderá carregar as imagens em padrão DICOM, efetuando mudanças leves em seu contraste, mas a imagem enviada precisa ser necessariamente a original. Além disso, a cada imagem armazenada, o técnico poderá criar uma mensagem informando pontos que achar pertinente para a avaliação do médico. Nesta tela, os botões salvar e enviar executam a tarefa de guardar as imagens com suas mensagens em um arquivo, que será enviado para o médico radiologista responsável. 


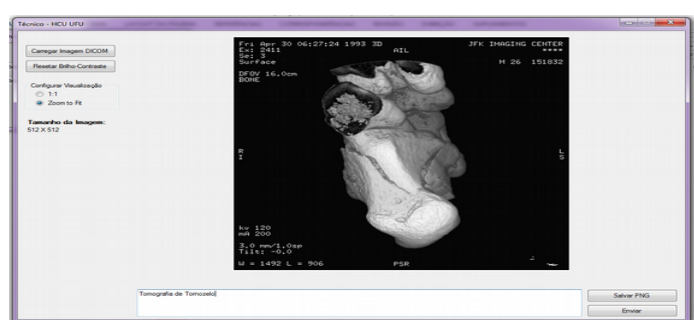

Figura 2 - Imagem da Tela Técnico do aplicativo Xlaudo.

A quarta é a Tela Médico. Nela o médico responsável pela avaliação das imagens, ao acessar o software, poderá abrir o arquivo com as imagens e as respectivas mensagens enviadas pelo técnico, mensagens estas que partem do médico que solicitou a opinião do especialista em radiologia. Após a análise pelo especialista, o exame, já com o laudo, é enviado de volta para que o técnico encaminhe ao médico responsável pelo atendimento do paciente. Nesta tela não existirá a opção carregar imagem, como existe na tela do técnico. No lugar deste comando, há a opção abrir imagem que executa a tarefa de abrir as imagens e as mensagens recebidas pelo técnico.

O armazenamento e compartilhamento destas imagens são realizados a partir de uma pasta compartilhada no serviço de armazenamento em nuvem Dropbox $^{\mathrm{TM}}$ em ambas as máquinas. A partir da comunicação serviço de armazenamento (software), as imagens e arquivos texto enviados podem ser acessados livremente por dois operadores.

\section{Resultados}

Criado para melhorar e agilizar a comunicação entre médicos de diferentes especialidades, para aprimorar e até complementar o diagnóstico de exames de raios- $\mathrm{X}$ e, assim, agilizar o tratamento adequado para o paciente, o aplicativo X-laudo que usa de compartilhamento de imagens médicas pelo software criado em linguagem C-Sharp no compilador Microsoft Visual Studio 2013, mostra resultados positivos. Sua eficiência nos detalhes de envio e reenvio possibilitam aos utilizadores uma interação rápida e fácil, fazendo assim, com que o diagnóstico por imagem em unidades básicas de saúde, onde não existem médicos radiologistas de plantão, seja mais eficiente. $\mathrm{O}$ uso da pasta compartilhada em nuvem também é uma vantagem no sentido de que o Software se torna leve e de melhor funcionamento. Desta forma, o serviço de saúde é otimizado, no que tange ao rápido diagnóstico e melhores opções de tratamento, além de evitar o deslocamento desnecessário, em alguns casos, de pacientes que podem ser tratados ligeiramente, principalmente quando o local de saúde que o atendeu disponibiliza do tratamento e recursos necessários, oferecendo agilidade no processo e confiabilidade.

\section{Discussão}

O uso do aplicativo X-laudo, embasado na telerradiologia, possui pontos conflitantes, principalmente para utilização deste em hospitais públicos. Para que o sistema seja implantado e executado eficientemente, existem necessidades de caráter físico e pessoal que devem existir e serem respeitadas.

Exemplo disso são as necessidades físicas. Para que seja possível a comunicação e manipulação das imagens, são necessários que existam, no mínimo, três computadores, com capacidade para processamento do sistema. Além disso, os computadores precisam estar conectados a uma rede de internet de boa qualidade e, também, ao sistema de dados do SUS para identificação de número do prontuário de cada paciente. Outra particularidade é a necessidade de monitores que possibilitem boa visualização das imagens geradas nos exames de rios-X, mesmo que o aplicativo permita visualizar a imagem alterando o brilho e contraste.

Outro ponto a ser discutido é a necessidade em relação aos que utilizam o aplicativo. Para efetivar o uso dele, é primordial que haja disposição para que os usuários queiram utilizar o software, assim como treinamento para melhor capacitá-los acerca das funções e ferramentas do X-laudo, assim como o respeito ao sigilo empregado no compartilhamento de imagens.

\section{Conclusão}

Ponderando os pontos citados nesse trabalho e, sabendo que a telerradiologia é uma área que gera grandes possibilidades de melhorar o desempenho do profissional da saúde em relação ao seu tratamento, o aplicativo X-laudo, mesmo sendo de grande complexidade, pode ser uma ferramenta poderosa no que tange à laudos e tratamentos corretos, visto que qualquer ser humano está sujeito a erros e, com o uso desse aplicativo, pode-se diminuir a porcentagem de erros sobre laudos em exames de raios-X. Porém, devese levar em consideração as dificuldades da implantação desse software nas unidades de saúde, como tecnologia usada, treinamento adequado e a prática do mesmo

\section{Agradecimentos}

Agradecemos à Professora Doutora Ana Claudia Patrocínio pela excelente didática na disciplina 
Telemedicina, além da sua força de vontade e amor ao ensino, que tange à orientação para este projeto.

\section{Referências}

[1]http:/www.infoescola.com/medicina/traumatologia/

[2]http://www.diagnostico.med.br/html/home/radiologia .php

[3]http://uniradio.vet.br/voce-sabe-o-que-e-

telerradiologia/ 